\title{
A PHARMACOLOGICAL STUDY ON THE ANTI-INFLAMMATORY EFFECTS OF CALENDULA OFFICINALIS EXTRACT ON EXPERIMENTAL ANIMALS
}

\author{
Dr. Ranjeet Kumar ${ }^{1}$, Dr. Sarju R Zilate ${ }^{1 *}$, Dr. Sushil Varma ${ }^{2}$, Mrs. Sweety Kumari ${ }^{3}$ \\ ${ }^{1}$ Asst. Professor, Department of Pharmacology, Raipur Institute of Medical Sciences (RIMS), Raipur, \\ CG, India \\ ${ }^{2}$ Professor, Department of Pharmacology, Mahatma Gandhi Institute of Medical Sciences \\ (MGIMS), Sevagram, Wardha, Maharashtra, India \\ ${ }^{3}$ Tutor, Department of Microbiology, Raipur Institute of Medical Sciences, Raipur, CG, India
}

Article Info: Received 24 March 2019; Accepted 26 April. 2019

Cite this article as: Kumar, R., Zilate, S., Varma, S., \& Kumari, S. (2019). A PHARMACOLOGICAL STUDY ON THE ANTI-INFLAMMATORY EFFECTS OF CALENDULA OFFICINALIS EXTRACT. Journal of Biomedical and Pharmaceutical Research, 8(2).

DOI: https://doi.org/10.32553/jbpr.v8i2.591

Address for Correspondence: Dr. Ranjeet Kumar, Asst. Professor, Department of Pharmacology, Raipur Institute of Medical Sciences (RIMS), Raipur, CG, India

Conflict of interest statement: No conflict of interest

\section{ABSTRACT:}

Introduction: Calendula officinalis is one of those plants which have medicinal importance due to its flowers has pharmacological activity the important pharmacological parameters have been less investigated properly and can be scientifically proved by reverse pharmacology. It was found of interest to evaluate these properties of extract of flowers of Calendula officinalis scientifically in experimental models.

Methods: Study was conducted in Albino Wistar rats.Fresh Calendula officinalis flowers were collected, extraction and drug formulation was made. Anti-inflammatory activity of hydroalcoholic extract of Calendula officinalis (HECO) flowers was studied in the Carrageenan induced paw edema model \& Cotton pellet induced granuloma models The differences between experimental groups were compared by ANOVA followed by Students " $\mathrm{t}$ " unpaired test.

Results: The Calendula officinalis extract of flowers at 200 and $400 \mathrm{mg} / \mathrm{kg}$ showed significant and highly significant inhibition ( $p<0.05$ and $p<0.001$, respectively) of paw edema after giving the carrageenan in the rat paw in comparison of control. In cotton pellets induced granuloma pouch method also, the Hydrochloric extract of Calendula officinalis (HECO) flowers showed very significant reduction of weight of granuloma $(\mathrm{p}<0.01)$ with $22.80 \%$ protection as compared with control.

Conclusion: We conclude that the Anti-inflammatory activity was noted with Hydrochloric extract of Calendula officinalis in a dose-dependent manner in acute (carrageenan-induced hind paw edema model) as well as sub-acute (cotton pellet induced granuloma model) inflammatory experimental models. They decrease the chemical mediators of inflammation

Key Words: Calendula Officinalis, anti inflammation, Paw Edema Model, granuloma pouch method, HECO 


\section{Introduction}

Ayurveda provides the knowledge to use the medicinal plants around us to combat with different diseases. "Herb" is a plant valued since ancient times for its medicinal, savory and aromatic qualities. It is one of the oldest medicinal cares for human since 4000-5000 B.C ${ }^{1}$. It played an important role in improving the quality of human life and maintaining human health for thousands of years. Drugs made from herbs have made their importance felt in the last few decades whose prevalence is continuously increasing in both developing and developed countries due to they are natural in origin and lesser side effects. ${ }^{2,3}$ It was also found during the periods of Charaka and Sushruta that many oral formulations of herbal medicines have been recommended for various pathologies and diseases. ${ }^{4}$ In medical text of Ayurveda, around 17,000 species are well documented in context of their biological and medicinal properties ${ }^{5}$. Plant extracts are potentially curative and also preventive. It can also augment body's defense against various invading agents and improve immunity ${ }^{6}$. Despite such intensive research on various herbal medicines, many species of plants are still left unexplored. Therefore, plants named Calendula officinalis is chosen for the present study. The different parts of Calendula officinalis have been found useful in a variety of symptoms and disorders. Calendula officinalis is one of those plants which have medicinal importance due to its flowering part has pharmacological activity. The plant is rich in many pharmaceutical active ingredients like carotenoids, auroxanthin, flavoxanthin ${ }^{7}$, flavonoids, glycosides, terpenoids esters, steroids and sterols, coumarins, amino acids. It is used as analgesic, antidiabetic, antiinflammatory, antiseptic, bactericide, in skin problems $^{8}$, and as antifungal agent ${ }^{9}$. In the UK, the decoction of the flowers was used as a potent drink for the treatment of smallpox and measles, fresh juice as a remedy for jaundice, costiveness (constipation) and suppression of menstrual flow ${ }^{10}$ Usefulness of Calendula officinalis was reported in the form of decoctions, infusions, tinctures in traditional systems of medicines for treating skin diseases like psoriasis, leprosy, etc. ${ }^{10,11,12,13 .}$ The important pharmacological parameters of Calendula officinalis have been less investigated properly and can be scientifically proved by reverse pharmacology. Therefore, it was found of interest to evaluate these properties of extract of flowers of Calendula officinalis scientifically in experimental models.

\section{Materials and methods}

The present study was conducted in experimental animals i.e. Albino Wistar rats. Animals were procured from Datta Meghe Institute of Medical Sciences, Sawangi (Meghe), Maharashtra after taking permission from Institutional animal ethical committee. The animals were caged in polyvinyl wire mesh cages in the central animal room of the institute approved by CPCSEA. They were maintained under standard laboratory condition (12-hour light and dark cycle and temperature of $22^{\circ} \mathrm{C} \pm 3^{0} \mathrm{C}$ ), humidity (60 \pm 10 $\%$ ) with access to food and water ad libitum according to OECD guidelines, revised draft guidelines 425 and by the Committee for the Purpose of Control and Supervision of Experiments on Animals (CPCSEA), Ministry of Social Justice and Empowerment, Government of India ${ }^{14}$. The animals were allowed to adapt to the new surrounding by giving rest of one week before subjecting them to experimentation.

Rats - Healthy Wistar rats of either sex weighing between180-250 grams (8 to12 weeks old) were used.

Drugs and Chemicals:

- Aspirin or Acetyl salicylic acid (Alkem Ltd.): A $2 \%$ suspension in gum acacia was prepared in distilled water. 
Dr. Ranjeet Kumar et al, Journal of Biomedical and Pharmaceutical Research

- Indomethacin (Jagsorpal Pharmaceutical Pvt. Ltd.): A 2\% suspension in gum acacia was prepared in distilled water.

- Carrageenan (Analar, BDH): 1\% carrageenan was prepared in NS on the day of experiment.

- Ketamine hydrochloride (NEON Laboratories limited thane).

Ethical Clearance

Ethical clearance was taken from Institutional Ethics Committee and Institutional Animal Ethics Committee (IAEC) before commencement of the study.

\section{Collection of plant material}

Fresh flowers of Plant Calendula officinalis were collected from the nearby area of Wardha and authenticated by $a$ local experienced botanist of Institute - JB COLLEGE OF SCIENCE, ( Janki Devi Bajaj College of Science ) WARDHA, MAHARASHTRA.The flowers were shade-dried, powdered in a electric mixture and stored in an air tight container for study.

Preparation of extract-

The hydro-alcoholic extracts were obtained by soxhlet extraction at $60^{\circ} \mathrm{C}$ using $70 \% \mathrm{v} / \mathrm{v}$ ethanol as a solvent. Extract obtained by this method was shed dried and yield was measured. Fresh solution was prepared by dissolving extract in distilled water before each experiment.

The yield of flowers extract by soxhlet extraction is $8 \mathrm{gm}$ from $40 \mathrm{gm}$ of powder.

\section{Preparation of drug formulation-}

For oral administration fresh solution was prepared by dissolving the Calendula officinalis flowers extract in distilled water before each experiment. Whereas for topical application Calendula officinalis flowers extract was mixed with simple ointment as mention below.

Preparation of ointment-
Simple ointment (100gm IP):

Soft Paraffin - 85 gm

Hard Paraffin -10

Lanolin/wool fat- $5 \mathrm{gm}$

$5 \%(w / w)$ ointment- $10 \%(w / w)$ ointment-

Simple ointment- 95gm

Simple ointment- 90gm

CO flowers extract-5 gm

CO flowers extract-10 gm

Assessment of anti-inflammatory activity

Anti-inflammatory activity of hydroalcoholic extract of Calendula officinalis flowers was studied in the following two models:

i) Carrageenan induced paw edema model

ii) Cotton pellet induced granuloma models

\section{Carrageenan-Induced Paw Edema Model ${ }^{15}$}

The albino Wistar rats of either sex were divided into 4 groups, 6 animals in each group (total 24). Group I served as control and was given only $2 \%$ gum acacia ( $10 \mathrm{ml} / \mathrm{kg}$, p.o.).

Group 1- Control- received distilled water $(10 \mathrm{ml} / \mathrm{Kg}$, p.o)

Group 2- HECO 200mg/kg orally

Group 3- HECO 400mg/kg orally

Group 4- Standard drug aspirin $300 \mathrm{mg} / \mathrm{kg}$ orally

Wistar rats of either sex weighing 150-250 grams were used for the test. Both hind paws were marked at tibio-talar junction. Right hind paw was kept as control in each animal. Acute inflammation was produced by sub-plantar injection of $0.1 \mathrm{ml}$ of $1 \%$ suspension of carrageenan with $2 \%$ gum acacia in normal saline, injected in left hind paw (planter aspect) after 60 minutes of oral administration of standard and test drugs. Each paw volume was measured by dipping in Mercury Plethysmometer upto the mark as described 
by Chattopadhyay et $a l^{16}$. Readings were taken at 1, 2 and 3 hour. The difference between the two readings was taken as the volume of edema and the inhibitory percentage of inflammatory reaction was determined for each animal by comparing with control and calculated by the formula described by Sudjarwo Agus ${ }^{17}$.

$\%$ inhibition $=(1-\mathrm{Et} / \mathrm{Ec}) \times 100^{17}$

Where, Ec = Edema of the control (group I).

$\mathrm{Et}=$ Edema of the treated (group II - IV).

\section{Cotton pellet-induced granuloma}

The albino Wistar rats of either sex were divided into 4 groups, 6 animals in each group (total 24 animals). Group I served as control and was given only $2 \%$ gum acacia $(10 \mathrm{ml} / \mathrm{kg}$, p.o.).

Group 1 Control- received distilled water (10ml/Kg, p.o)

\section{Group 2- HECO 200mg/kg orally}

Group 3- HECO 400mg/kg orally

Group 4- Standard drug indomethacin $10 \mathrm{mg} / \mathrm{kg}$ orally

Sterile cotton pellet $(2 \pm 1 \mathrm{mg})$ soaked in $0.2 \mathrm{ml}$ of distilled water containing penicillin $(0.1 \mathrm{mg})$ was implanted subcutaneously on the first day in the inner side of right thigh of each rat with aseptic precautions under ketamine $(60 \mathrm{mg} / \mathrm{kg}$ i.p) anesthesia ${ }^{18}$. Animals were given test and standard drug orally once a daily for 7 days. The pellets were remained in bodies of rats for 7 days. On $8^{\text {th }}$ day the rats were sacrificed and wet cotton pellets with granuloma were dissected out. Weights of these cotton pellets were measured. Then they were dried in hot air oven at $60^{\circ} \mathrm{C}$ for 24 hours and again the dry weight was determined. Change in weight of granuloma was calculated by subtracting weight of cotton.
Statistical analysis

All the results were expressed as Mean \pm Standard Deviation (SD). The differences between experimental groups were compared by one-way Analysis of Variance (ANOVA) followed by Students " $\mathrm{t}$ " unpaired test. The results were considered statistically significant when $* p<0.05, * * p<0.01$-very significant, $* * * p<0.001$-Highly significant as compare to control.

\section{Observations and Results}

\section{Carrageenan-Induced Paw Edema Model}

The Calendula officinalis extract of flowers at 200 and $400 \mathrm{mg} / \mathrm{kg}$ showed significant and highly significant inhibition $(p<0.05$ and $p<0.001$, respectively) of paw edema at end of $1^{\text {st }}$ hour after giving the carrageenan in the rat paw in comparison of control. At the $1^{\text {st }}$ hour, the doses of 200 and $400 \mathrm{mg} / \mathrm{kg}$ showed percentage inhibition $4.54 \%$, and $16.67 \%$ in comparison of control. (Table 1 \& Graph 1 )

On the other hand, the Calendula officinalis extract of flowers at 200 and $400 \mathrm{mg} / \mathrm{kg}$ respectively showed highly significant inhibition $(p<0.001)$ of paw edema at end of $2^{\text {nd }}$ and $3^{\text {rd }}$ hour after giving the carrageenan in the rat paw in comparison of control. At the $2^{\text {nd }}$ hour, the doses of 200 and $400 \mathrm{mg} / \mathrm{kg}$ showed percentage inhibition $39.47 \%$ and $46.05 \%$ in comparison of control and at the end of $3^{\text {rd }}$ hour, the graded doses of Calendula officinalis showed percentage inhibition of $48.05 \%$ and $59.74 \%$ in comparison with control. Whereas the standard drug aspirin showed highly significant inhibition of paw edema of rat $(p<0.001)$ at $1^{\text {st }}, 2^{\text {nd }}$ and $3^{\text {rd }}$ hour with percentage inhibition of $30.30 \%, 59.21$ and $74.02 \%$, respectively in comparison of control. (Table - 1 \& Graph 1 ) 
Dr. Ranjeet Kumar et al, Journal of Biomedical and Pharmaceutical Research

Table 1: Anti-inflammatory activity hydroalcoholic flowers extract of calendula officinalis by Carrageenan induced paw edema method in rats.

\begin{tabular}{|l|l|l|l|l|l|}
\hline \multirow{2}{*}{ Group } & $\begin{array}{l}\text { Dose } \mathrm{mg} / \mathrm{kg} \\
\text { PO }\end{array}$ & \multicolumn{4}{|l|}{ Paw Volume(ml) (Percentage Inhibition) } \\
\cline { 3 - 6 } & & $0 \mathrm{Hr}$ & $1 \mathrm{Hr}$ & $2 \mathrm{Hr}$ & 3. \\
\hline 1-Control Distilled Water & $10 \mathrm{ml} / \mathrm{kg}$ & $0.63 \pm 0.01$ & $0.66 \pm 0.01$ & $0.76 \pm 0.008$ & $0.77 \pm 0.01$ \\
\hline 2-HECO & 200 & $\begin{array}{l}0.64 \pm 0.010 \\
(1.58)\end{array}$ & $\begin{array}{l}0.63 \pm 0.001^{* *} \\
(4.54)\end{array}$ & $\begin{array}{l}0.46 \pm 0.011^{* * *} \\
(39.47)\end{array}$ & $\begin{array}{l}0.40 \pm 0.01^{* * *} \\
(48.05)\end{array}$ \\
\hline 3-HECO & 400 & $\begin{array}{l}0.62 \pm 0.01 \\
(1.58)\end{array}$ & $\begin{array}{l}0.55 \pm 0.01^{* * *} \\
(16.67)\end{array}$ & $\begin{array}{l}0.41 \pm 0.01^{* * *} \\
(46.05)\end{array}$ & $\begin{array}{l}0.31 \pm 0.007^{* * *} \\
(59.74)\end{array}$ \\
\hline 4-Standard Aspirin & 300 & $\begin{array}{l}0.62 \pm 0.005 \\
(1.59)\end{array}$ & $\begin{array}{l}0.46 \pm 0.008^{* * *} \\
(30.30)\end{array}$ & $\begin{array}{l}0.31 \pm 0.02^{* * *} \\
(59.21)\end{array}$ & $\begin{array}{l}0.20 \pm 0.01^{* * *} \\
(74.02)\end{array}$ \\
\hline
\end{tabular}

Note: Number of animals $n=6$. One-way ANOVA followed by Student's " $t$ " unpaired test. Results are expressed in Mean \pm SEM: $* p<0.05$ - significant, $* * p<0.01$ - very significant and $* * * p<0.001$ - highly significant as compared to control. HECO-Hydroalcoholic extract of Calendula officinalis flowers.

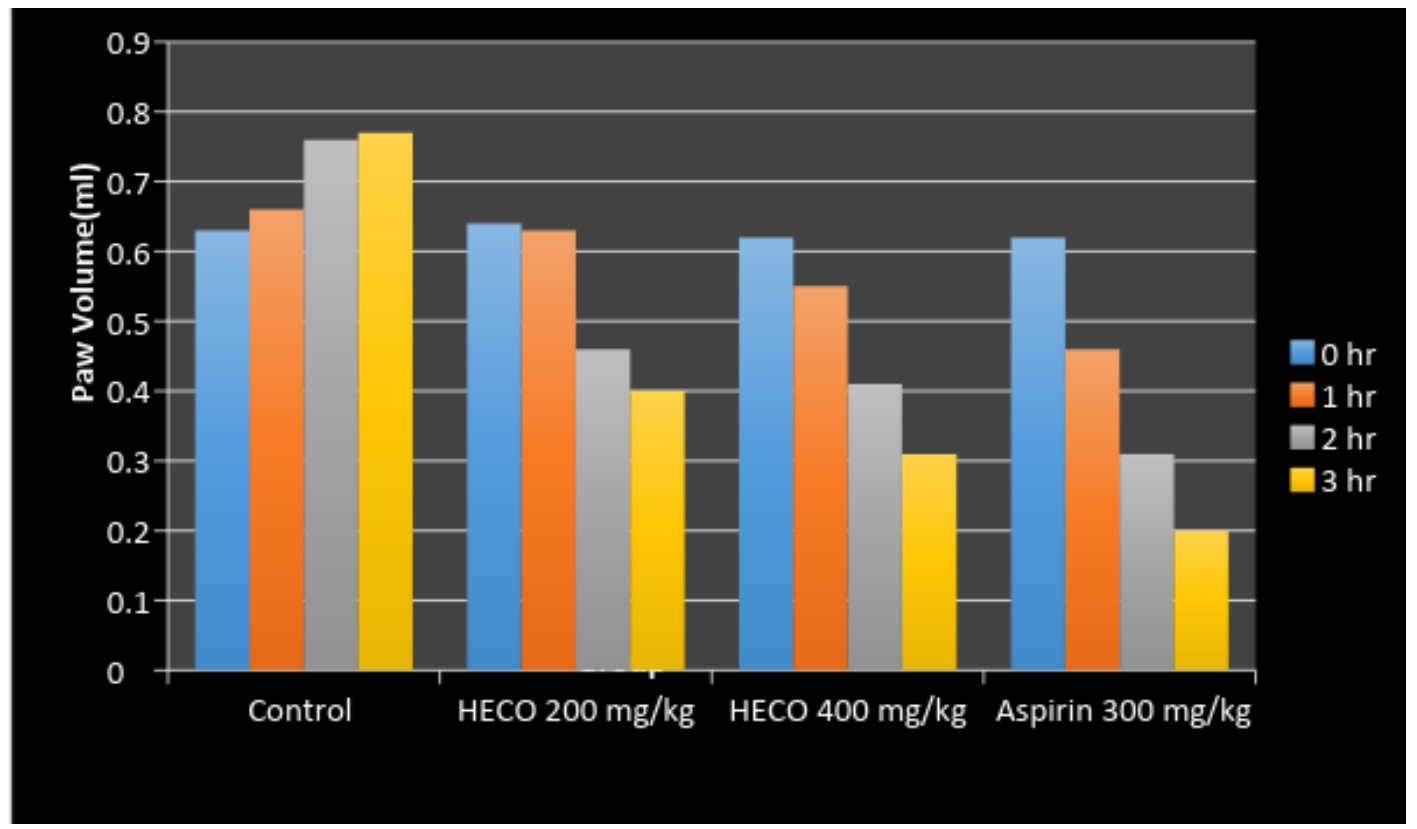

Graph 1: Anti-inflammatory activity of hydroalcoholicflowers extract of Calendula officinalis by Carrageenan induced paw edema method in rats.

\section{Cotton pellet induced granuloma pouch model}

In cotton pellets induced granuloma pouch method, the hydroalcoholic extract of Calendula officinalis flowers at $200 \mathrm{mg} / \mathrm{kg}$ showed very significant reduction of weight of granuloma $(p<0.01)$ with $22.80 \%$ protection as compared with control. On the other hand, $400 \mathrm{mg} / \mathrm{kg}$ showed highly significant reduction $(\mathrm{p}<0.001)$ in the weights of granuloma with $41.64 \%$ protection in comparison with control. The standard, indomethacin $20 \mathrm{mg} / \mathrm{kg}$ showed a protection of $63.75 \%$ with highly significant reduction $(p<0.001$ ) in the weight of granuloma as compared with control. ( Table 2 \& Graph 2 ) 
Dr. Ranjeet Kumar et al, Journal of Biomedical and Pharmaceutical Research

Table 2: Anti-inflammatory activity of hydroalcoholic flowers extract of calendula officinalis by cotton pellet induced granuloma method in rats

\begin{tabular}{|l|l|l|l|l|l|}
\hline Group & $\begin{array}{l}\text { Drug Treatment } \\
\mathrm{mg} / \mathrm{kg} \text { orally }\end{array}$ & $\begin{array}{l}\text { Initial dry wt of } \\
\mathrm{CP}(\mathrm{mg})\end{array}$ & $\begin{array}{l}\text { Final dry wt } \\
\text { of } \mathrm{CP}(\mathrm{mg})\end{array}$ & $\begin{array}{l}\text { Wt of granulomatous } \\
\text { tissue }\end{array}$ & \% Inhibition \\
\hline $\begin{array}{l}\text { 1-Control Distilled } \\
\text { Water }\end{array}$ & $10 \mathrm{ml} / \mathrm{kg}$ & 2 & $30.50 \pm 1.87$ & $28.50 \pm 1.87$ & \\
\hline 2-HECO & 200 & 2 & $24 \pm 1.26$ & $22 \pm 1.26^{* * *}$ & $22.81 \%$ \\
\hline 3-HECO & 400 & 2 & $17.00 \pm 2.09$ & $15.00 \pm 2.09^{* * *}$ & $47.37 \%$ \\
\hline $\begin{array}{l}\text { 4-Standard } \\
\text { Indomethacin }\end{array}$ & 10 & 2 & $12.33 \pm 1.50$ & $10.33 \pm 1.50^{* * *}$ & $63.75 \%$ \\
\hline
\end{tabular}

a. $t$ cannot be computed because the standard deviations of both groups are 0

Note: Number of animals $n=6$. One-way ANOVA followed by Student's " $t$ " unpaired test. Results are expressed in Mean \pm SEM: ${ }^{*} p<0.05$ - significant, $* * p<0.01$ - very significant and $* * * p<0.001$ - highly significant as compared to control. HECO-Hydroalcoholic extract of Calendula officinalis flowers.

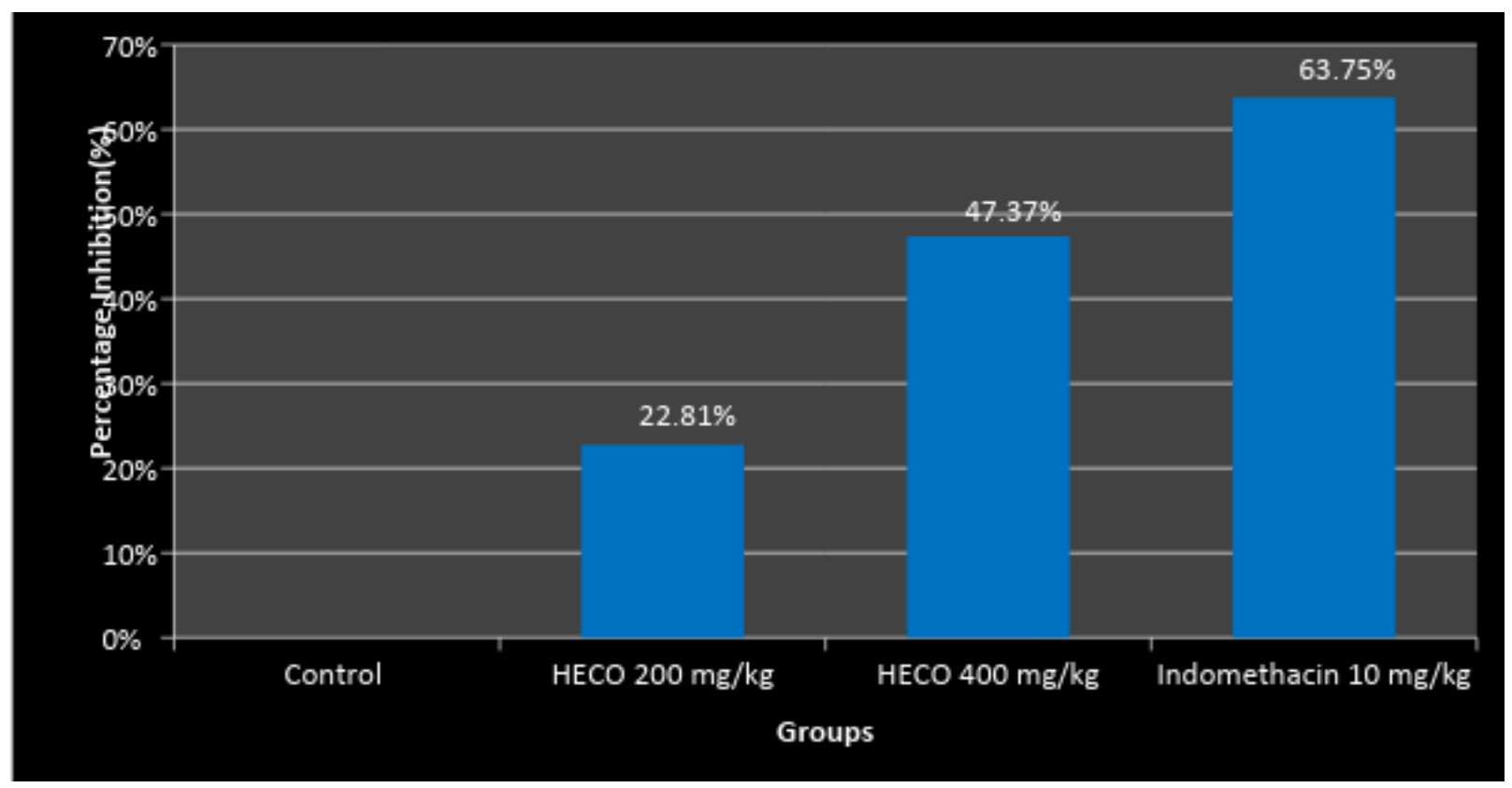

Graph 2: Anti-inflammatory activity of hydroalcoholic flowers extract of Calendula officinalis on rats by cotton pellet induced granuloma showing percentage inhibition.

\section{Discussion}

\section{Carrageenan-induced paw edema ${ }^{19,20,21,22}$}

An anti-inflammatory drug of herbal origin is suitable for screening of anti-inflammatory properties in the acute as well as sub-acute model of inflammation ${ }^{19}$. Carrageenan model is commonly used as it is highly reproducible with apparent no systemic side effects. ${ }^{20}$

Carrageenan develops edema in the paw of rat in a biphasic event. ${ }^{21}$ The initial phase of inflammation produced by carrageenan causes release of histamine, kinin and serotonin in the first hour. While the second phase is related to the release of prostaglandin like substances, protease and lysosome in 2-3 hour and these mediators produce edema in rat paw. ${ }^{21,22}$ These mediators leads to a dilation of vessels with extravasations of fluid and plasma proteins with formation of edema. These mediators as the metabolites of arachidonic acid (AA) and its COX pathway are capable of 
producing the characteristic signs of inflammation: vasodilatation, hyperemia, pain, edema, and cellular filtration.

Oral administration of HECO extract at the dose $200 \mathrm{mg} / \mathrm{kg}$ and 400mg $/ \mathrm{kg}$ showed significant $(p<0.001)$ percent inhibition of edema at the end of 2 and 3 hours as compare to control. (Table 1, graph 1 ) This action may be due to inhibition of histamine, serotonin, kinin and prostaglandin by HECO. The carotenoids present in Calendula officinalis flowers like lycopene has been reported to consistently reduce transcript levels of proinflammatory cytokines (Herzog et al,2005). Moreover, the expression of cyclooxygenase-2, a key enzyme involved in inflammatory process was found to be initiated by the treatment of extract. Thus, the Calendula officinalis flower extract may be contributes to its antiinflammatory activity through the inhibition of mediators of inflammation especially proinflammatory cytokines as well as by the inhibiting the Cox-2 and thereby prostaglandins which has major role in inflammatory process.

\section{The cotton pellet-induced granuloma}

It is widely used to assess the exudative and proliferative component of inflammation. Cotton pellets by absorbing fluid greatly influence the weight of granuloma and dry weight. It is well corrected with the amount of granulomatous tissue ${ }^{23}$. The size of granuloma is inhibited by NSAIDs by suppressing the generation of collagen fiber and mucopolysaccharides. ${ }^{24} \mathrm{HECO}$ at the dose of 200 and $400 \mathrm{mg} / \mathrm{kg}$ showed significant $(p<0.01$ and $p<0.001$ respectively) inhibition of granuloma as compare to control (Table 2). The percentage inhibition of granuloma at dose of $400 \mathrm{mg} / \mathrm{kg}$ of HECO is almost comparable to the standard, Aspirin. With increasing doses of HECO, there is a gradual increase in the percentage inhibition of granuloma, indicating its anti-inflammatory activity.Calendula officinalis flowers extract contain flavonoids and genins ${ }^{25}$ as constituents which may be responsible for decreasing both final dry weight of cotton pellet and weight of granuloma which can attribute to their antiinflammatory activity.

\section{Conclusions}

We conclude that the Anti-inflammatory activity was noted with HECO in a dosedependent manner in acute (carrageenaninduced hind paw edema model) as well as sub-acute (cotton pellet induced granuloma model) inflammatory experimental models. The anti-inflammatory activity of HECO is due to its constituents, flavonoids and triterpenoids. They decrease the chemical mediators of inflammation. Further studies can give more strong correlation and association of $\mathrm{HECO}$ with anti-inflammation and can be utilize in Health care.

\section{Acknowledgements}

We would like to thank Professor \& Head, Dept. of Pharmacology, MGIMS Medical College, Sevagram, Wardha for his always available guidance to us.

\section{Funding: No funding sources}

Ethical approval: The study was approved by the Institutional Ethics Committee.

\section{References}

1. Kashikar VS, Pooja P. Available online through Formulation and evaluation of taste masked chewable herbal tablet for cough remedy. Int J Res Ayurveda Pharm. 2011;2(14):830-3.

2. Kumar KLS, Mustapha MH, Rajbhandari $A$, Ramakrishnan R. Phytochemical and Pharmacological Studies on Achillea Millefolium ( L ) Leaves. Res J Pharm Biol Chem Sci. 2011;2(1):24-30.

3. Mukherjee PK, Maiti K, Mukherjee K, Houghton PJ. Leads from Indian medicinal plants with hypoglycemic potentials. J Ethnopharmacol. 2006 Jun 15;106(1):128. 
Dr. Ranjeet Kumar et al, Journal of Biomedical and Pharmaceutical Research

4. Aslam, M., Jafri, M.A., Kalim, Javed SS. Plant drug with hypoglycemic activity. In: Glimpses in plant Research. New Delhi: Today and Tomorrow's Printers and Publishers; 1998. p. 271-99.

5. Kala C, Dhyani P, Sajwan B. Developing the medicinal plants sector in northern India: challenges and opportunities. J Ethnobiol Ethnomed. 2006;2:32-46.

6. Singh B, Bhat TK, Singh B. Potential therapeutic applications of some antinutritional plant secondary metabolites. J Agric Food Chem. 2003 Sep 10;51(19):5579-97.

7. Bakó E, Deli J, Tóth G. HPLC study on the carotenoid composition of Calendula products. J Biochem Biophys Methods. Jan;53(1-3):241-50.

8. Dumenil G, Chemli R, Balansard C, Guiraud $H$, Lallemand $M$. [Evaluation of antibacterial properties of marigold flowers (Calendula officinalis L.) and mother homeopathic tinctures of $\mathrm{C}$. officinalis L. and C. arvensis L. (author's transl)]. Ann Pharm françaises. 1980 Jan;38(6):493-9.

9. Kasiram. Antifungal Activity Of Calendula Officinalis. Indian Journal of Pharmaceutical Sciences. 2000. p. 464.

10. Horvath, Ferenc, inventors. (1992). Therapeutical compositions against psoriasis. "US Patent 5165932" Nov 24.

11. Zahra A, Mohammed A, Mohammed H. Evaluation of the immunomodulatory effects of five herbal plants. J Ethnopharmacol. 2000 Sep;72(1-2):16772.

12. Cordova CAS, Siqueira IR, Netto $C A$, Yunes RA, Volpato AM, Cechinel Filho $V$, et al. Protective properties of butanolic extract of the Calendula officinalis L. (marigold) against lipid peroxidation of rat liver microsomes and action as free radical scavenger. Redox Rep. 2002 Jan;7(2):95102.
13. Harrison D. Natural therapeutic composition for the treatment of wounds and sores. 2003.

14. OECD guidelines for the testing of chemicals. Acute Oral Toxicity: Up - and Down Procedure) [Internet] 1998 [updated 1998 Sep 21; cited 2013 Oct 08]. Available from: http://http://iccvam.niehs. nih.gov/SuppDocs/Fed Docs/OECD/ OECDt g425.pdf.

15. Winter CA, Risley EA, Nuss GW. Carrageenin-induced edema in hind paw of the rat as an assay for antiinflammatory drugs. Proc Soc Exp Biol Med. 1962;111:544-7.

16. Chattopadhyay RN, Chattopadhyay RR, Roy S, Maitra SK. A simple method for plethysmometric measurement of paw volume of small laboratory animals in the evaluation of anti-inflammatory effect. Bull Calcutta Sch Trop Med. 1986;34:5-8.

17. Agus S. The Potency of Piperine As Antiinflammatory and Analgesic in rats and mice. Folia Med Indonesiana. 2005;41:190-4.

18. Youth RA, Simmerman SJ, Newell R, King RA. Ketamine anesthesia for rats. Physiol Behav. 1973;10:633-6.

19. Akah PA, Okogun Jl, Ekpendu TO. Antioedema and analgesic activity of Diodia scandans extract in rats and mice. Phytother. Res.Phytother. Res., 1993;7:317-9.

20. Di Rosa M, Giroud JP, Willoughby DA. Studies of the mediators of the acute inflammatory response induced in rats in different sites by carrageenan and turpentine. J. Pathol. 1971;104(1):15-29.

21. Vinegar R, Schreiber $W$, Hugo R. Biphasic development of carrageenan edema in rats. J. pharmacol. Exp. Ther. 1969;166(1):96-103.

22. Crunkhorn $P$, Meacock SCR. Mediators of the inflammation induced in the rat paw by carrageenan. Brit. J. Pharmacol 1971;42(3):392-402. 
Dr. Ranjeet Kumar et al, Journal of Biomedical and Pharmaceutical Research

23. Panthong $A$, Kanjanapothi $D$, Taesotikul $T$, Phankummoon A, Panthong K, Reutrakul $\mathrm{V}$. The anti-inflammatory activity of Ventilago harmandiana Pierre. J. Ethnopharmacol 2004;91;237-42.

24. Lonac $M$, Parnham MJ, Plauchithiu $M$, Brune K. Oxaceprol An atypical inhibitor of inflammation and joint damage. Pharmacol. Res. 1996;33:367-73.

25. Della LR, Della LR, Tubaro $A$, Sosa $S$, Becker $H$, Saar $S$, Isaac $O$. The role of triterpenoids in topical anti-inflammatory activity of Calendula officinalis flowers. Planta Med, 1994; 60: 516-520. 